\title{
Three-Phase Regenerative Electronic Load to Test Shunt Power Conditioners
}

\author{
C. Roncero-Clemente, Student Member, IEEE, M.I Milanés-Montero, Member, IEEE, V.M. Miñambres-Marcos, Member, \\ IEEE, E. Romero-Cadaval, Senior Member, IEEE
}

Power Electrical \& Electronic Systems (PE\&ES), School of Industrial Engineering, University of Extremadura. Badajoz, Spain

\begin{abstract}
A 3-phase regenerative electronic load to test shunt equipments such as active power filters and power conditioners at high power levels is presented in this paper. The electronic load is composed by two inverters with a common DC- bus. One inverter draws from the grid a configurable load current with the harmonic and imbalance desired levels, and the other one is used to inject the energy into the grid trying to minimize the losses, while the active filter performance is being tested. The control strategies and the current controller for both inverters are explained. Simulations and experimental results showing the proper operation of the electronic load to test shunt power conditioners are presented.
\end{abstract}

\section{INTRODUCTION}

Some electronic devices, such as uninterruptible power systems (UPS), power supplies or energy storage systems need to be tested in a load bank to check the behavior of the equipment and to improve its reliability and stability [1].

Other devices which need a load bank to be tested are active power filters and power conditioners (PC). These equipments are connected in parallel with nonlinear loads in order to compensate reactive power and harmonic and unbalanced currents demanded by the load.

The load bank is usually designed with dissipative components, resistors, inductors and capacitors, which generate a lot of power losses, heat and few possibilities to carry out variable tests. For high power applications these power losses are unacceptable [2].

Electronic loads have been developed and commercialized [3] to extend the conditions of the test with constant power, constant current or constant voltage modes of operation, and even behaving as non lineal loads [4]. This development is very important to test active power filters and power conditioners. However, they all have the drawback of consuming a great amount of energy during the tests. Also, some authors [5-7] have developed control algorithms for electronic loads simulators, achieving better performance and effectiveness.

At high power levels another aspect to improve is the energy recycling during the tests. Whit this objective, simulators have been implemented considering the energy regeneration and trying to emulate a variety of load characteristics. Tests energy are fed back to the power grid with little loss and high power factor. These simulators have been designed with a topology made by two electronic converters, with a common DC bus [8,9]. A lot of control strategies have also been implemented as repetitive control strategies to manage these simulated devices [10].
There are few research works about active loads with energy recycling and only experimental small-scale prototypes or simulators can be found. In high power applications it is necessary to develop regenerative type active electronic loads to return the power to the grid, with these characteristics:

- Highly energy-efficient system, since the energy can be returned back to the utility, so a large amount of energy can be saved during test procedures. It is especially advantageous in case of high-power equipments.

- Compact size, because the active regeneration scheme allows reduction on passive power components and associated cooling system. According to it, the size can be reduced as compared to the conventional scheme.

- Flexible dc control design: the system typically requires a front-end ac-dc converter and a regenerative dc-ac inverter. The controller can be flexibly designed with dc link voltage either controlled by the converter or by the inverter [11].

The electronic loads with energy recycling found in the literature are designed and controlled to test series equipments, as different types of power supplies. In order to test parallel equipments at high power levels, it is essential the performance of an energy feed-back electronic load with the capability of choosing the harmonic and imbalance levels of the current demanded from the grid. With this objective, this paper presents the design of a 3-phase regenerative electronic load to be able to conduct tests of shunt equipments for high power applications. Simulations and experimental results are presented to validate the operation of the load to test a shunt power conditioner to improve the power quality.

\section{REGENERATIVE ELECTRONIC LOAD TOPOLOGY WITH AN ACTIVE FILTER CONNECTED IN PARALLEL}

Fig. 1 shows the electronic load scheme, composed by two electronic converters with a common DC bus, with a power conditioner connected in parallel to be tested. One inverter demands from the grid a load current while the other inverter injects the energy into the grid. The topology of a 3-phase regenerative $\mathrm{AC}$ electronic load is displayed in Fig. 2. The values of the parameters of the electronic load are summarized in Table I. 


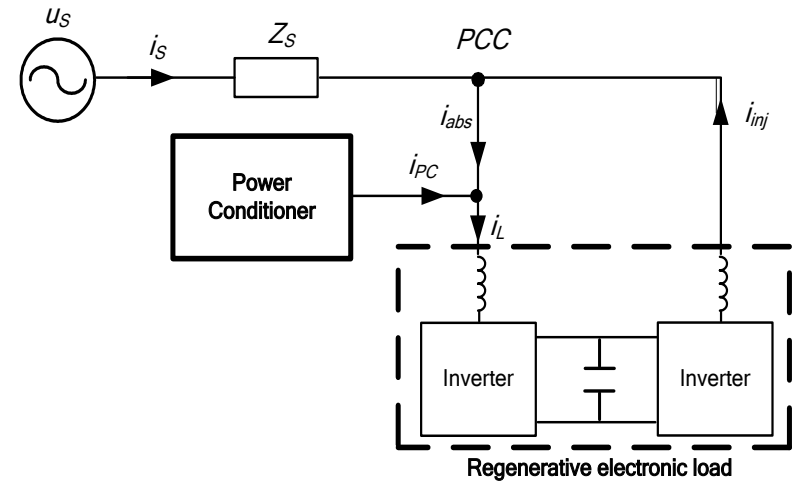

Fig. 1. Electric scheme of the regenerative electronic load and shunt power conditioner.

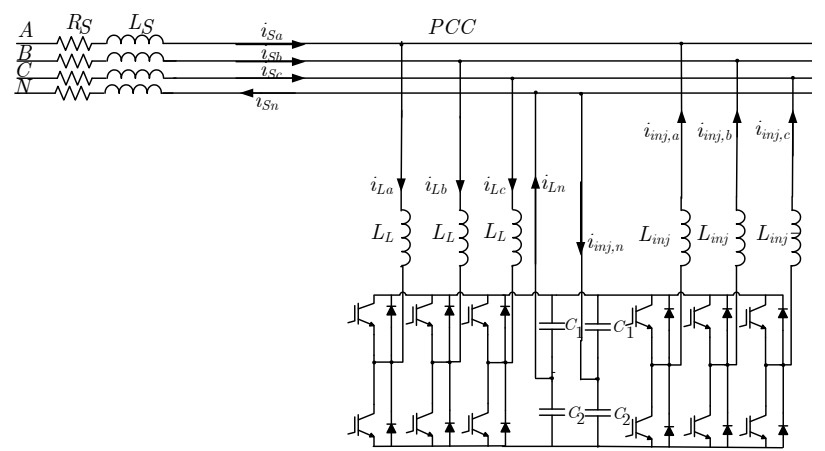

Fig. 2. Three-phase regenerative electronic load topology.

TABLE I

PARAMETERS OF THE REGENERATIVE ELECTRONIC LOAD

\begin{tabular}{|c|c|c|c|c|}
\hline$U_{n}(\mathrm{~V})$ & $I_{n}(\mathrm{~A})$ & $S_{n}(\mathrm{kVA})$ & $C_{l}(\mathrm{mF})$ & $C_{2}(\mathrm{mF})$ \\
\hline 400 & 200 & 100 & 28,2 & 28,2 \\
\hline $\begin{array}{c}U_{d c, \text { ref }} \\
(\mathrm{V})\end{array}$ & $\begin{array}{c}f_{s, \text { max }, \text { load }} \\
(\mathrm{kHz})\end{array}$ & $\begin{array}{c}f_{s, \text { max }, \text { inj }} \\
(\mathrm{kHz})\end{array}$ & $L_{\text {load }}(\mathrm{mH})$ & $L_{\text {inj }}(\mathrm{mH})$ \\
\hline 800 & 10 & 20 & 3 & 1,75 \\
\hline
\end{tabular}

Each electronic converter is a 3 branches inverter with midpoint DC bus. Each branch is connected to the grid with a filter inductor, $L_{L}$ or $L_{i n j}$, and the middle point of the DC bus is connected to the neutral conductor directly, with no impedance.

\section{ELECTRONIC LOAD CONTROL STRATEGY}

The first inverter is used as programmable load. To control this converter a friendly application in Simulink (Fig.3 (a) and Fig.3 (b)) is developed, which allows introducing the desired load current specifications. The parameters that can be introduced are the $R M S$ value, the harmonic order, the phase angle and the sequence for each component. With all of these parameters one can compose the reference load current with the harmonic and/or imbalance levels needed.

The developed block needs the angle of the positive sequence fundamental component of the voltage at the point of common coupling (PCC). It is attained with the Autoadjustable Synchronous Reference Frame (ASRF) block [12] shown in Fig. 3(a), which needs the measurements of the PCC voltages $u_{P C C}(a, b, c)$.

The second inverter is used to inject the energy into the grid. To generate the reference injection current it is necessary to analyze the circuit shown in Fig.2. Applying the First Kirchhoff law in the circuit, one has:

$$
i_{S}+i_{i n j}=i_{L}
$$

where $i_{S}$ is the current supply, $i_{i n j}$ is the reference injection current and $i_{L}$ is theload current.

Despising the losses $\left(i_{S} \approx 0\right)$, it is obtained:

$$
i_{i n j}=i_{L} \text {. }
$$

Also the control of DC bus is required. This control will be done by the injector device. For this reason a new term is included in (2):

$$
i_{i n j}=i_{L}-k_{C}(s)\left(U_{d c, r e f}-U_{d c, \text { meas }}\right) u_{p c c_{1}^{+}},
$$

where $U_{d c, \text { ref }}$ is the reference DC bus voltage, $U_{d c m e a s}$ is the measured DC bus voltage, $u_{p c c_{1}^{+}}$is the positive-sequence fundamental component of the PCC voltage and $k c(s)$ is the transfer function of a proportional-integer (PI) controller.

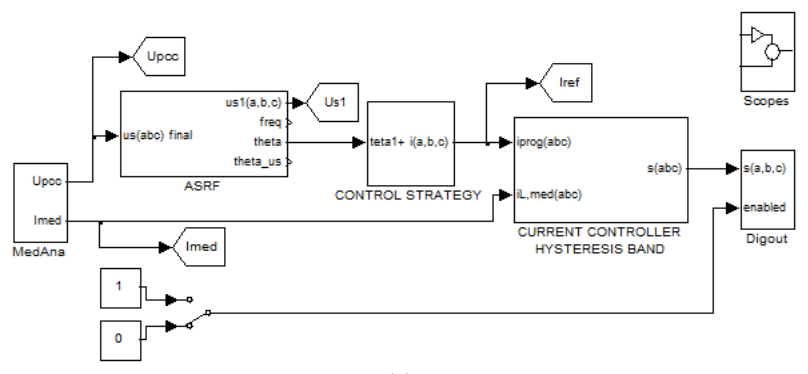

(a)

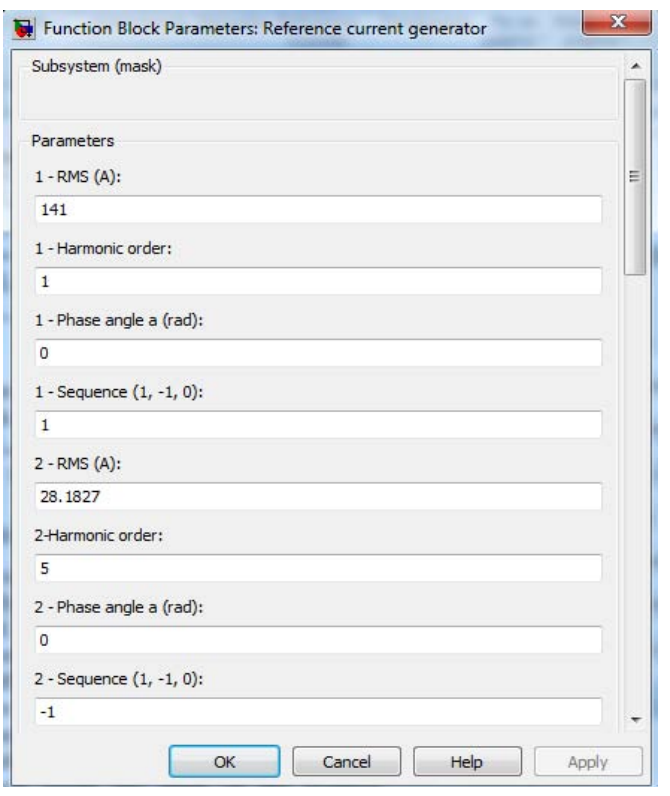

(b)

Fig. 3. Programmable load: (a) Control block. (b) Data entry screen. 


\section{ELECTRONIC LOAD CURRENT CONTROLLER}

As controller technique to track the reference current, a hysteresis band (see Fig.4) has been employed. This technique compares the reference current with the measured current, and depending on the error the switching signals of the IGBT's are generated. The same tracking technique has been implemented for the programmable load and for the injector.

The operation of the tracking technique for the injector is displayed in Fig. 5. If the error is positive, the injector must inject a greater value of current (positive slope), so the upper IGBT of the inverter branch must be closed and the lower IGBT must be open. The inverse operation is needed (negative slope) in case of a negative error.

\section{ELECTRONIC LOAD SIMULATION RESUlTS}

The $100 \mathrm{kVA}$ three-phase regenerative electronic load operation has been simulated using Matlab/Simulink with the topology shown in Fig. 2 and the parameters collected in table 1. To improve the injector reference current tracking the inductance of the injector is half that of the load and the injector switching frequency is twice that of the load.

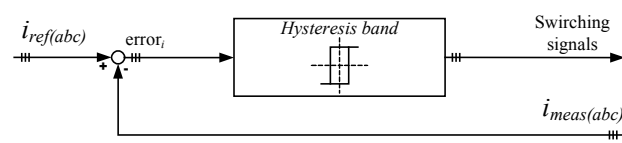

(a)

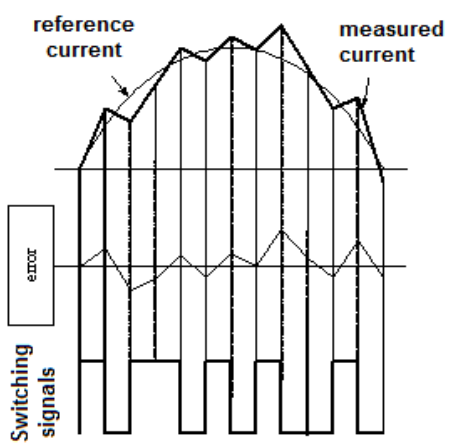

(b)

Fig. 4. Hysteresis band controller.

\begin{tabular}{|c|c|c|c|}
\hline Error & Situation & Switching signal & \multicolumn{2}{|c|}{ Scheme } \\
\hline & & Top IGBT: & $\frac{U_{t_{c}}}{2}$ \\
\hline
\end{tabular}

Fig. 5. Injector control modes.
The simulation tests of the electronic load in case of distorted and unbalanced conditions are shown in the following sections.

A. Current with harmonic content $(h=1, h=5$ and $h=7)$

The reference current of the load in this case is programmed with an individual harmonic distortion of $I H D_{5}=20 \%$ and $I H D_{7}=14,28 \%$ respectively. The $R M S$ value of the fundamental component is $141 \mathrm{~A}$. The reference load current and the demanded load current are shown in Fig. 6 where it can be seen an appropriate tracking. Below, in Fig. 7 they are displayed the reference current and injected current by the injector to recycle the energy. Finally, the current supply $R M S$ value is shown in Fig. 8. The energy recovery ratio is over the $90 \%$.

\section{B. Unbalanced current}

In this case, the electronic load with energy recycling is tested with an unbalanced current. The unbalanced ratios are $I^{-} / I^{+}=22 \%$ and $I^{0} / I^{+}=28,8 \%$. The $R M S$ value of the positivesequence component is $115 \mathrm{~A}$. The reference load current and the demanded current are shown in Fig.9. In Fig. 10, they are displayed the reference current and injected current by the injector. The energy recover ratio is similar to the one obtained in the first test.

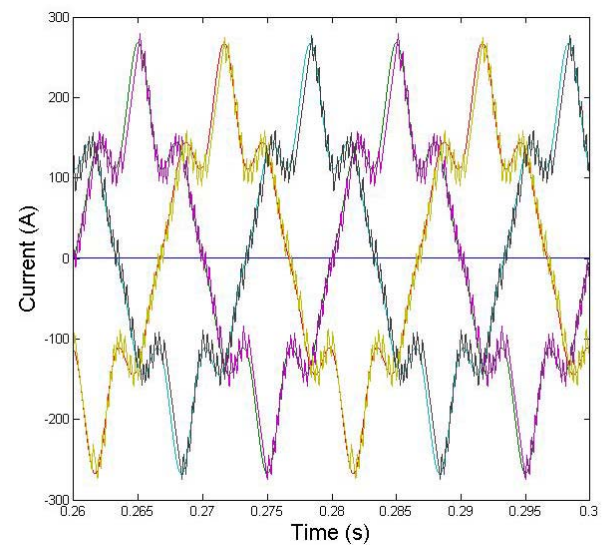

Fig. 6. Reference and demanded load current under distorted conditions (simulation case A).

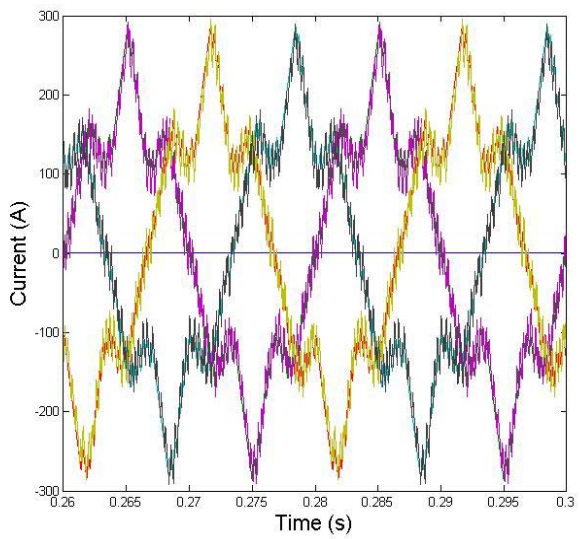

Fig. 7. Reference and injected injector current under distorted conditions (simulation case A). 


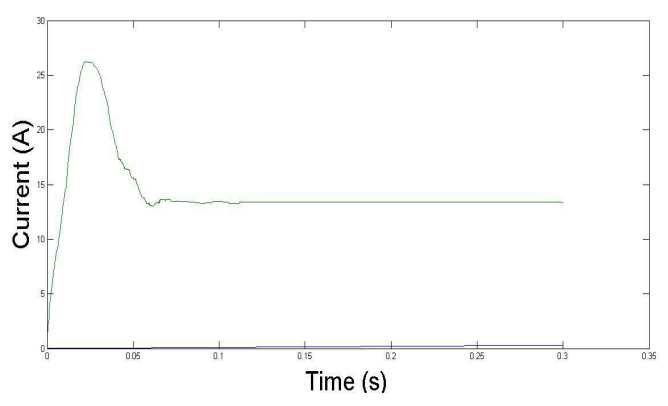

Fig. 8. Supply RMS current under distorted conditions (simulation case A).

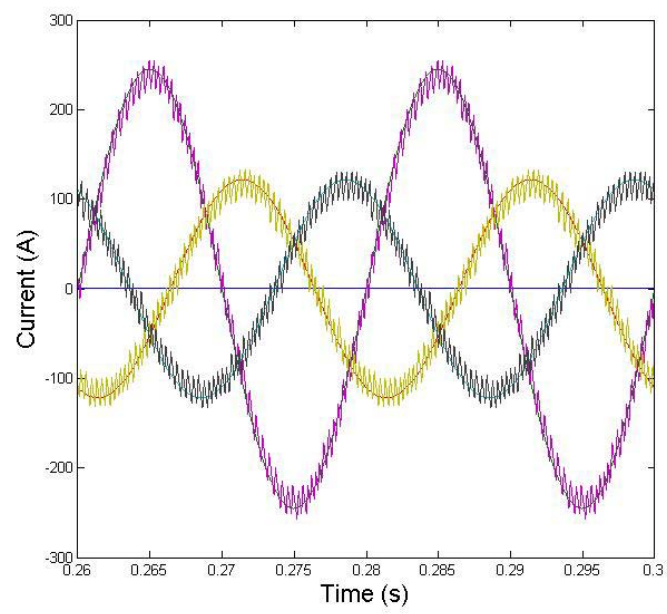

Fig. 9. Reference and demanded load current under unbalanced conditions (simulation case B).

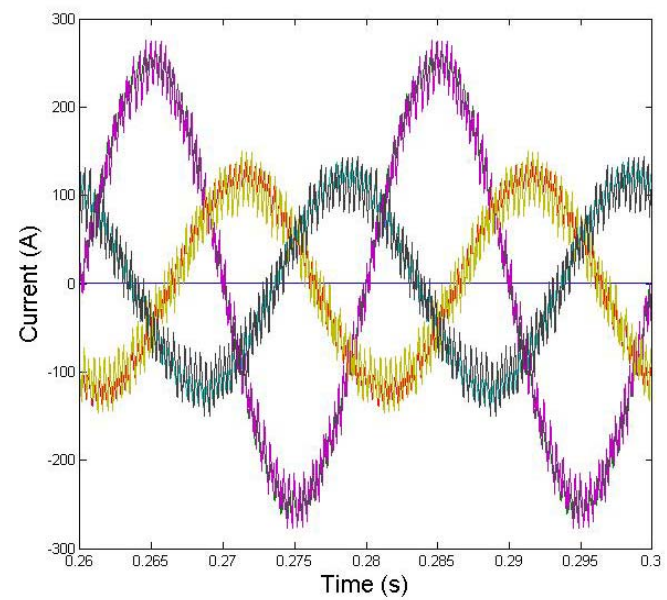

Fig. 10. Reference and injected injector current under unbalanced conditions (simulation case B).

VI. APPLICATION OF THE REGENERATIVE ELECTRONIC LOAD TO TEST POWER CONDITIONERS. SIMULATIONS RESULTS.

In this section an application of the electronic load to test shunt equipments is presented. A power conditioner connected in parallel with the regenerative load has been tested according to the scheme in Fig. 1.
The power conditioner topology is a 3 branches inverter with middle point DC bus (see Fig. 11). This device is used to correct the harmonics and unbalanced currents demanded from the grid by nonlinear loads and to compensate reactive power to improve the power factor.

In the power conditioner a Perfect Harmonic Cancelation (PHC) [13] control strategy has been implemented needing the positive sequence fundamental component of the PCC voltage. This value is provided by an ASRF.

The topologies and connection of the shunt power conditioner and regenerative load are presented in Fig. 11. Simulations have been conducted using Matlab/Simulink. The simulations parameters are summarized in Table II.

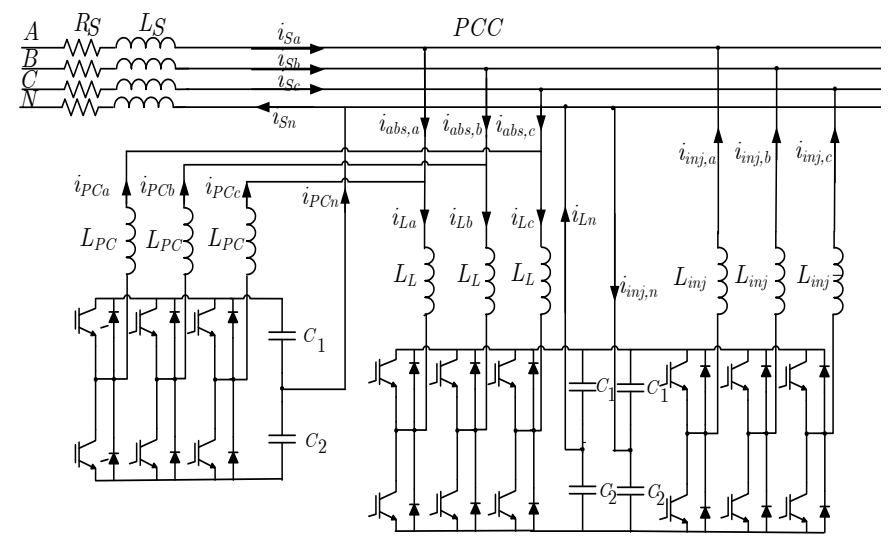

Fig. 11. Regenerative electronic load and shunt power conditioner topologies.

TABLE II

DEVICES PARAMETERS IN THE SIMULATION

\begin{tabular}{|c|c|c|c|c|}
\hline$U_{n}(\mathrm{~V})$ & $I_{n}(\mathrm{~A})$ & $S_{n}(\mathrm{kVA})$ & $C_{I}(\mathrm{mF})$ & $C_{2}(\mathrm{mF})$ \\
\hline 400 & 200 & 100 & 28,2 & 28,2 \\
\hline $\begin{array}{c}U_{d c, \text { ref (load) }} \\
(\mathrm{V})\end{array}$ & $\begin{array}{c}U_{d c, \text { ref (PC) }} \\
(\mathrm{V})\end{array}$ & $\begin{array}{c}f_{s, \text { max }, \text { load }} \\
(\mathrm{kHz})\end{array}$ & $\begin{array}{c}f_{s, \text { max }, \text { inj }} \\
(\mathrm{kHz})\end{array}$ & $\begin{array}{c}f_{s, \text { max }, P C} \\
(\mathrm{kHz})\end{array}$ \\
\hline 800 & 800 & 10 & 20 & 20 \\
\hline$L_{L}(\mathrm{mH})$ & $L_{i n j}(\mathrm{mH})$ & $L_{P C}(\mathrm{mH})$ & & \\
\hline 3 & 1,75 & 1,75 & & \\
\hline
\end{tabular}

The proper operation of the regenerative electronic load, when testing the performance of the power conditioner in case of a distorted and balanced nonlinear load is presented.

The harmonic content of the load current in this test is the same as that presented in section $\mathrm{V}$, case $\mathrm{A}$. The reference load and demanded load currents are shown in Fig. 12. In Fig. 13 the compensation current of the power conditioner is displayed. The current demanded from the grid, $i_{a b s}$ in Fig. 1 and Fig. 11, once the power conditioner is operating is presented in Fig. 14. As the power conditioner is responsible for the harmonic components of the load current, this current is sinusoidal and balanced, validating the good performance of the power conditioner. Finally, Fig. 15 shows the injector current in order to recycle the energy into the grid. This current is also sinusoidal and balanced due to the operation of the power conditioner. 


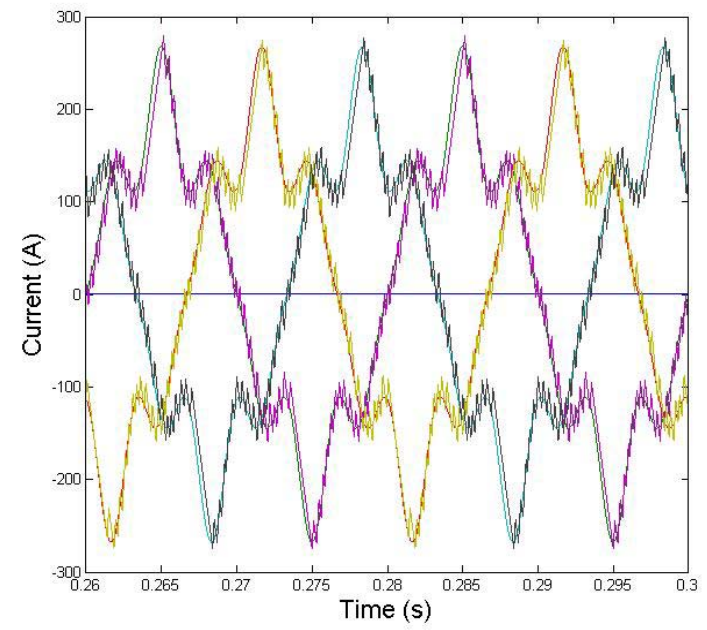

Fig. 12. Reference load current and demanded current to test the power conditioner operation $\left(i_{L}\right)$.

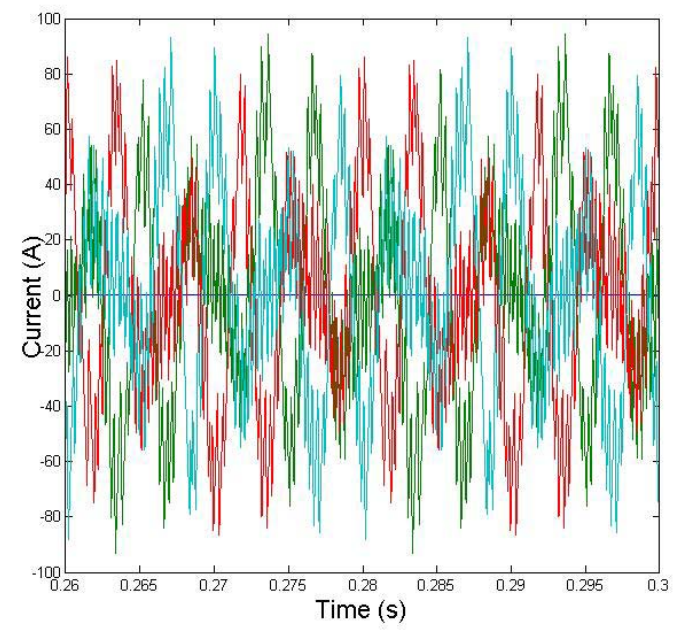

Fig. 13. Power conditioner compensation current $\left(i_{P C}\right)$.

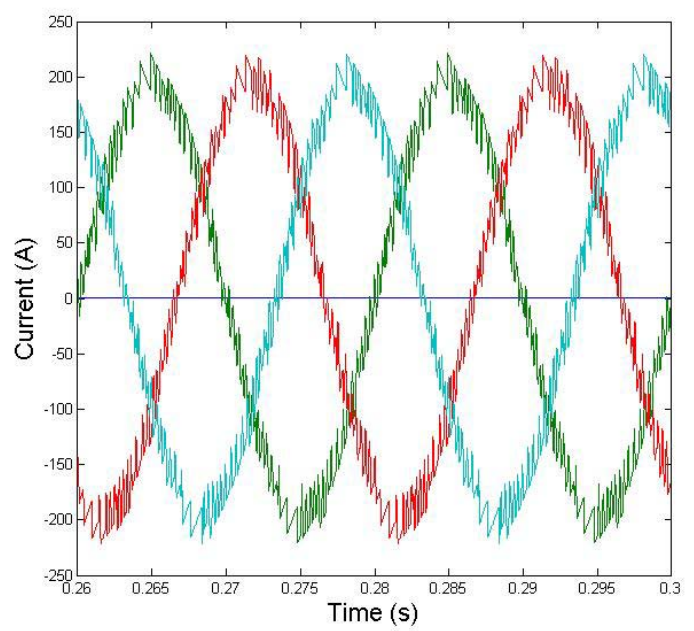

Fig. 14. Demanded current from the grid while the power conditioner operation test $\left(i_{a b s}\right)$.

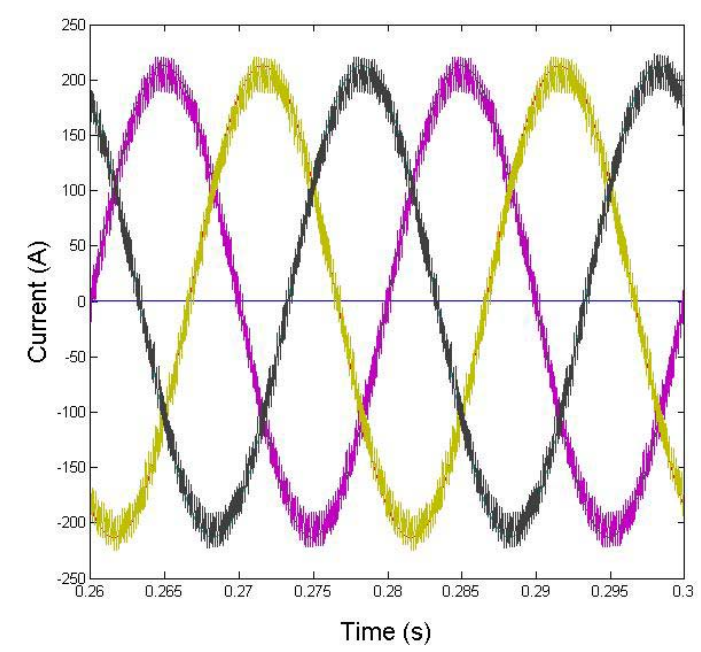

Fig. 15. Injected current into the grid by the regenerative load while the power conditioner operation test $\left(i_{i n j}\right)$.

\section{APPLICATION OF THE REGENERATIVE ELECTRONIC LOAD TO TEST POWER CONDITIONERS. EXPERIMENTAL RESULTS}

The electronics converters used in the experimental test are 3 branches inverter by Semikron with hall effect sensors of current in each arm and voltage sensors to capture the middle point DC bus and PCC voltages.

Each inverter branch is connected to the grid with a filter inductor, $L_{L}, L_{i n j}$ and $L_{P C}$ respectively, and the middle point of the DC bus is connected to the neutral conductor directly, following the topologies shown in Fig. 11.

XPC Target from Matlab/Simulink has been used as control platform. Three industrial PCs have been used as Target to run the presented models in real time, equipped with data acquisition cards (DAQ's), and one PC is used as Host to control the other PCs.

The experimental test has been conducted at low power level with the parameters shown in table 3. The programmed load current has a harmonic content equal as the presented in the simulation tests, but with a $R M S$ fundamental component value reduced to $1,5 \mathrm{~A}$.

Due to XPC Target control platform limitations, the switching frequency has been decreased to $4 \mathrm{kHz}$. In Fig. 16 the experimental prototypes used to carry out the test are shown and the experimental results are displayed in Fig. 17. In this figure they are presented, from top to bottom, the source current, $i_{a b s}$, the injected current, $i_{i n j}$, the programmable load current, $i_{L}$ and the power conditioner current, $i_{P C}$. One can notice that the source current and injected current are sinusoidal without harmonics, since the harmonic components of the load current are delivered by the power conditioner. Also, the source current is in phase with the positive-sequence fundamental component of the source voltage, attaining an unity displacement power factor. 
TABLE III

DEVICES PARAMETERS IN THE EXPERIMENTAL TEST

\begin{tabular}{|c|c|c|c|c|}
\hline$U_{n}(\mathrm{~V})$ & $I_{n}(\mathrm{~A})$ & $S_{n}(\mathrm{VA})$ & $C_{l}(\mathrm{mF})$ & $C_{2}(\mathrm{mF})$ \\
\hline 30 & 1,5 & 135 & 28,2 & 28,2 \\
\hline $\begin{array}{c}U_{d c, \text { ref (load) }} \\
(\mathrm{V})\end{array}$ & $\begin{array}{c}U_{d c, \text { ref (PC) }}(\mathrm{V}) \\
f_{s, \text { max }, \text { load }} \\
(\mathrm{kHz})\end{array}$ & $\begin{array}{c}f_{\text {s, } \text { max }, \text { inj }} \\
(\mathrm{kHz})\end{array}$ & $\begin{array}{c}f_{s, \text { max }, P C} \\
(\mathrm{kHz})\end{array}$ \\
\hline 120 & 120 & 4 & 4 & 4 \\
\hline$L_{\text {load }}(\mathrm{mH})$ & $L_{\text {inj }}(\mathrm{mH})$ & $L_{P C}(\mathrm{mH})$ & & \\
\hline 3 & 1,75 & 1,75 & & \\
\hline
\end{tabular}

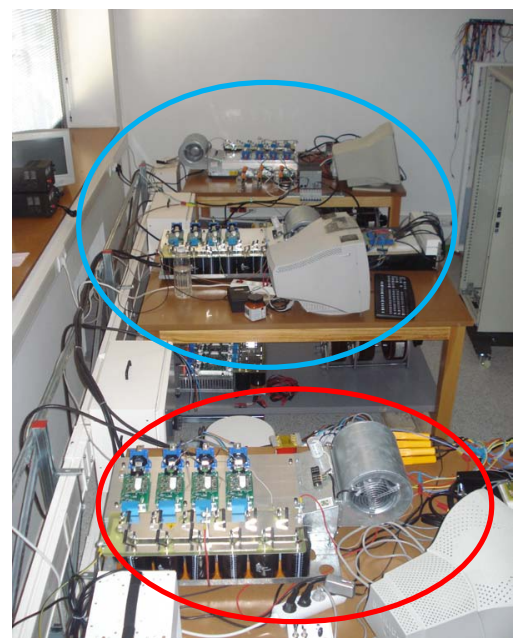

Fig. 16. Experimental prototypes: power conditioner (highlighted in red) and regenerative electronic load (highlighted in blue).

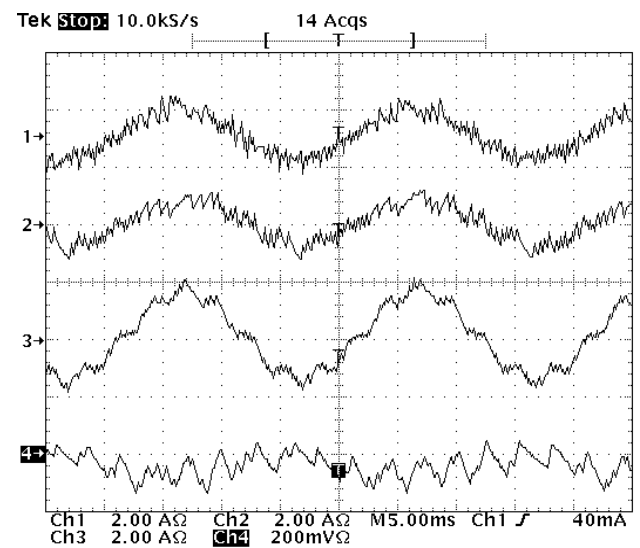

Fig. 17. Experimental results. From top to bottom: source current, $i_{a b s}$, injected current, $i_{i n j}$, programmable load current, $i_{L}$ and power conditioner current, $i_{P C}$.

\section{CONCLUSIONS}

This paper has presented the design and control of a threephase regenerative programmable electronic load to be used to test shunt electronic devices for high power applications. Simulation results of the electronic load under distorted and unbalanced conditions at high power levels are shown. The application of the regenerative load to test a power conditioner is verified by simulation at high power levels and experimentally with a small-scale laboratory prototype.

\section{ACKNOLEDGMENTS}

The authors gratefully acknowledge the financial support provided by the Junta de Extremadura (Regional Government), Spain, under project PDT08A046.

\section{REFERENCES}

[1] M.T. Tsai. C. Tsai. "Energy Recycling for Electrical AC Power Source Burn-In Test". IEEE Transactions on Industrial Electronics, Vol. 47, No. 4 pp 974-976. 2000

[2] Ju- Won Baek; Myung- Hyo Ryoo; Jong Hyun Kim; Jih- Sheng Lai. "50 kVA Regenerative Active Load for power test system". European Conference on Power Electronics and Applications. pp 1-8. 2007.

[3] Z. Rong; C. Jian; "Repetitive control algorithms for a real-time dynamic electronic load simulator". Conference and Exposition on Applied Power Electronics APEC'06. Twenty-First Annual IEEE. 2006.

[4] M. Kazerani "A high-performance controllable AC load". 34th Annual Conference on Industrial electronics. IECON. pp 442.447. 2008.

[5] Y. Srinavasa Rao; M. Chandorkar, "Rapid Prototyping Tool for Electrical Load Emulaion using Power Electronic Converters". Conference on Thermal Phenomena in Electronic Systems, 1996. pp 352- 358. 1996.

[6] H. Akagi, Y. Kanazawa, A. Nabae. " Instantaneous reactive power compensators comprising switching devices without energy storage components". IEEE Transaction on Industrial Electronic. Vol. IA-20, $\mathrm{n}^{\mathrm{o}} 22$. pp.625. 1984.

[7] M.Y. Chang, Jiann-Yow Lin, Y. Tzou. "DSP- based fully digital control of a AC/DC converter with a nonlinear digital current mode control". IEEE PESC Conference. pp 721-726. 1994.

[8] W. Shaokun, H. Zhenyi, P. Chuanbiao. " A repetitive control strategy of AC electronic load with energy recycling”. International Technology and Innovation Conference ITIC. pp 1-4. 2009.

[9] Z. Kai, Kang Yong; X. Jian; et al. "Direct repetitive control of SPWM inverter for UPS purpose. IEEE Transactions on Power Electronics. pp 784792. 2003.

[10] J. Zhao, S. Pan; X. Wang. " High Power Energy Feedback AC Electronic Load and its Application in Power System Dynamic Physical Simulation". Conference on Industry Application. 42 nd IAS Annual Meeting. pp 2303-2310. 2007.

[11] J. Baek, M. H. Ryoo, J. Hyun, K. Jih-Sheng Lai. “ 50 kVA Regenerative Active load for power test system". European Conference on Power Electronics and Applications. pp 1-8. 2007.

[12] M.I. Milanes-Montero; E. Romero-Cadaval; A. Rico; V. MiñambresMarcos; F. Barrero-González. "Novel method for synchronization to disturbed three-phase and single-phase systems". IEEE International Symposium on Industrial Electronics. Junio, 2007.

[13] M.I Milanés Montero, E. Romero Cadaval, F. Barrero Cadaval. "Comparison of Control Strategies for Shunt Active Power Filters in ThreePhase Four- Wire Systems". IEEE Transactions on Power Electronics. Vol.22, pp. 229-236. Enero 2007. 